Gut, 1972, 13, 99-102

\title{
Effect of truncal vagotomy on acid and pepsin: Response to a cholinergic drug in man
}

\author{
D. J. COWLEY
}

From the Department of Surgery, Royal Postgraduate Medical School, Hammersmith Hospital, London

SUMMARY The gastric output of acid and pepsin in response to two doses of the cholinergic drug carbachol was measured before and two months after complete truncal vagotomy and pyloroplasty in eight patients with duodenal ulcer.

After vagotomy the basal output of acid and pepsin was reduced and there was no stimulation of secretion by a subthreshold dose of carbachol $(0.5$ units $/ \mathrm{kg})$ nor was there an increase in the response to a submaximal dose of carbachol $(2 \cdot 0$ units $/ \mathrm{kg})$.

Cannon's criteria for denervation supersensitivity of an organ were not obeyed with regard to acid or pepsin secretion.

Andersson and Grossman (1965) studied the effect of graded doses of urecholine (bethanechol) on the acid and pepsin secretion from Pavlov pouches in dogs before and after vagal denervation of the pouch by dividing the septum between the pouch and the main stomach. They found that the pepsin output of the pouch in response to submaximal doses of urecholine was increased significantly after vagotomy, indicating that vagotomy had made the peptic cells supersensitive to cholinergic stimuli.

Tinker (1969) proposed that if this phenomenon occurred in human subjects it could form the basis of a test for the completeness of vagotomy. In such a test criteria for supersensitivity derived from the law of denervation (Cannon, 1939) would be applied to the response of the peptic cells to cholinergic stimuli before and after vagotomy. The development of supersensitivity would indicate that the peptic cells had been vagally denervated (decentralized). Denervation supersensitivity is demonstrated by these criteria when an organ responds to subthreshold doses, which, by definition, have no effect on the innervated organ, and when the response of the organ to submaximal doses is increased.

The present study was designed to investigate Tinker's proposal in human subjects with duodenal ulcer by determining their gastric acid and pepsin response to subthreshold and submaximal doses of the cholinergic drug carbachol before and after denervation of the stomach by truncal vagotomy.

Received for publication 1 November 1971.

\section{Materials and Methods}

Ten men with chronic duodenal ulcer were tested shortly before and two months after truncal vagotomy and Heineke-Mikulicz pyloroplasty. In each test, after an overnight fast, a radioopaque nasogastric tube was passed and adjusted under fluoroscopic control so that the tip lay in the most dependent part of the stomach. The resting juice was aspirated and discarded and gastric juice then aspirated continuously into ice-cooled containers by low-grade suction. Collections were made at 15 -minute intervals throughout the test.

After a one-hour basal collection carbachol, 0.5 $\mu \mathrm{g} / \mathrm{kg}$, was injected subcutaneously and gastric juice was collected for a second hour. Carbachol, $2 \cdot 0 \mu \mathrm{g} / \mathrm{kg}$, was then injected and gastric juice collected for a third hour. It was found early in the study that doses larger than $2.0 \mu \mathrm{g} / \mathrm{kg}$ were liable to cause abdominal colic and profuse sweating, and therefore these larger doses were not tested further.

The volume of each 15-minute sample was measured and the titratable acidity was determined by titrating $1 \mathrm{ml}$ samples to $\mathrm{pH} 7$ with an autoburet (Radiometer, Copenhagen) using $\mathrm{N} / 10 \mathrm{NaOH}$. The concentration of pepsin in each 15-minute sample was determined by the method of Grossman and Marks (1960) using radioiodinated serum albumin as substrate. In expressing the results the total outputs of acid and pepsin secreted in each hour were calculated by adding together the four 15-minute outputs. On other days, before vagotomy and two months after vagotomy, the peak acid output to both 
insulin $0.2 \mathrm{u} / \mathrm{kg}\left(\mathrm{PAO}_{\mathrm{I}}\right)$ and pentagastrin $6 \mu \mathrm{g} / \mathrm{kg}$ (PAO $_{\mathbf{P G}}$ ) was measured in a combined test (Baron, 1969). Completeness of vagotomy was determined by the criteria of Hollander (1948).

The statistical significance of the mean difference between the response to a given dose of carbachol before and after complete vagotomy was determined using Student's t test for paired data. Statistical significance was assumed for values of $P<0.05$.

\section{Results}

Two patients had an incomplete vagotomy and their results were excluded; consequently the statistical analysis was confined to the results from the remaining eight patients.

\section{SECRETION OF ACID}

In the eight patients grouped together when tested before vagotomy neither 0.5 nor $2.0 \mu / \mathrm{kg}$ of carbachol significantly stimulated acid output above basal levels. However, in five individual patients carbachol, $2.0 \mu \mathrm{g} / \mathrm{kg}$, caused a significant increase in acid output above basal levels $(\mathrm{P}<0.05)$, while $0.5 \mu \mathrm{g} / \mathrm{kg}$ did not stimulate secretion. In this group, which has been analysed separately (Fig. 1), carbachol $2 \cdot 0$ $\mu \mathrm{g} / \mathrm{kg}$ was therefore a submaximal dose, whilst carbachol $0.5 \mu \mathrm{g} / \mathrm{kg}$ was a subthreshold dose. After vagotomy in these five patients a highly significant reduction of acid output occurred in the basal hour $(69 \%, P=0.03)$ and also after carbachol $0.5 \mu \mathrm{g} / \mathrm{kg}$ $(74 \%, \mathrm{P}=0.007)$ and $2.0 \mu \mathrm{g} / \mathrm{kg}(69 \%, \mathrm{P}=0.003)$. Similar significant reductions were found in the corresfonding periods for all eight patients.

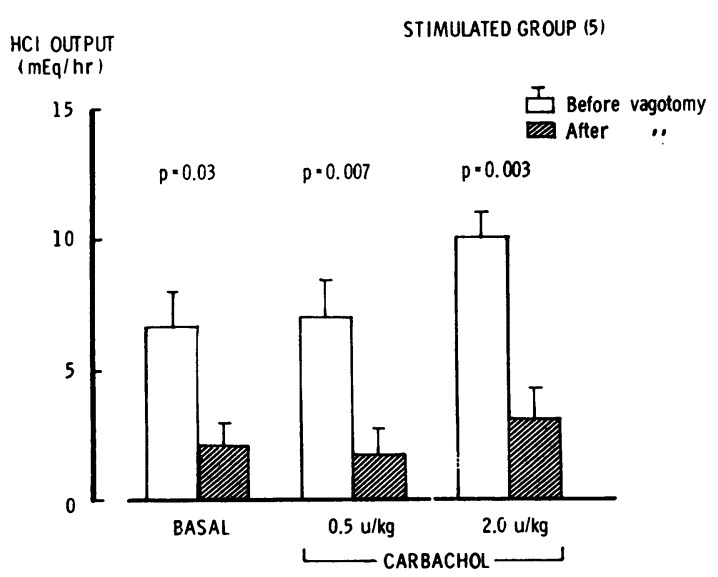

Fig. 1 Mean acid output before and after truncal vagotomy in the five patients in whom carbachol, $2.0 \mu \mathrm{g} / \mathrm{kg}$, stimulated secretion. Means and standard errors of the mean are shown.

\section{SECRETION OF PEPSIN}

Pepsin output was stimulated preoperatively by carbachol $2.0 \mu \mathrm{g} / \mathrm{kg}$ in the same five individuals and the results for this subgroup were analysed separately (Fig. 2) from the results of all the eight patients.

\section{STIMULATED GROUP (5)}

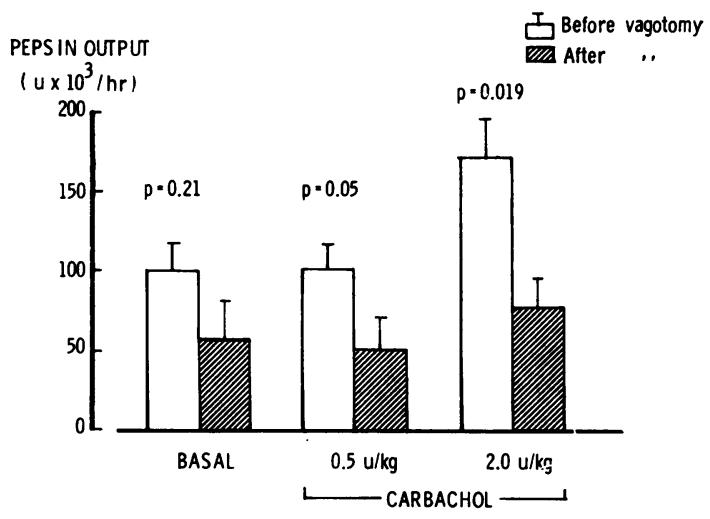

Fig. 2 Mean pepsin output before and after truncal vagotomy in the five patients in whom carbachol, $2.0 \mu \mathrm{g} / \mathrm{kg}$, stimulated secretion. Means and standard errors of the mean are shown.

After vagotomy in the five patients pepsin output was reduced but not significantly by $44 \%(P=0 \cdot 21)$ in the basal hour, but there was a significant reduction after carbachol of $0.5 \mu \mathrm{g} / \mathrm{kg}(50 \%, \mathrm{P}=0.05)$ and $2 \cdot 0 \mu \mathrm{g} / \mathrm{kg}(55 \%, \mathrm{P}=0.019)$. Similar reductions of pepsin output after vagotomy were found in the corresponding periods for all eight patients. The basal pepsin output formed a considerable proportion of the total pepsin output after both doses of carbachol. If the basal pepsin output was subtracted from the total there was no response to carbachol $0.5 \mu \mathrm{g} / \mathrm{kg}$ and the reduction in pepsin output after vagotomy was due solely to a reduction of the basal output. However, in the group of patients whose pepsin output was stimulated by carbachol $2 \cdot 0$ $\mu \mathrm{g} / \mathrm{kg}$ there was a real reduction in the response to this dose after vagotomy. After subtracting basal levels in this group the mean prevagotomy pepsin output was $69 \times 10^{3} \mathrm{u} / \mathrm{hr}$ and after vagotomy $19 \times 10^{3} \mathrm{u} / \mathrm{hr}$, a reduction of $73 \%(\mathrm{P}<0.05)$. The pepsin concentrations before and after vagotomy are shown in Figure 3. The mean pepsin concentration in the basal periods and after the two doses of carbachol was apparently lower after vagotomy, but the differences were not statistically significant. 


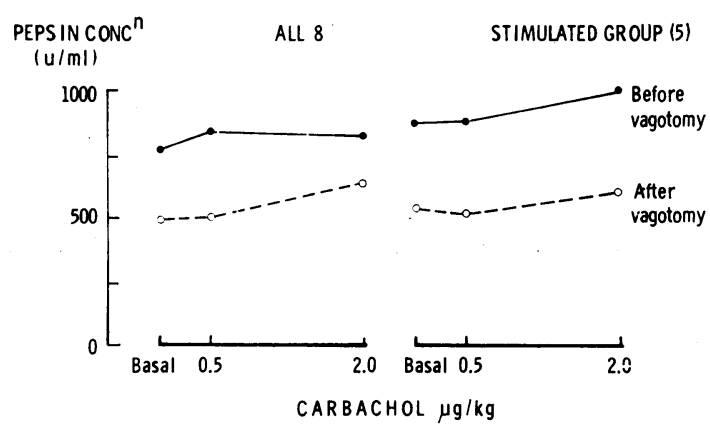

Fig. 3 Mean pepsin concentration before and after truncal vagotomy in all eight patients studied and in the five patients in whom carbachol, $2 \cdot 0 \mu \mathrm{g} / \mathrm{kg}$, stimulated secretion.

In eight patients the peak acid output in response to insulin was reduced from $41.28 \mathrm{~m}$-equiv/ $\mathrm{hr}$ before vagotomy to $2 \cdot 320 \mathrm{~m}$-equiv $/ \mathrm{hr}$, ie, basal levels, after vagotomy. The peak acid output in response to pentagastrin was reduced from $47.90 \mathrm{~m}$-equiv $/ \mathrm{hr}$ before vagotomy to $16.90 \mathrm{~m}$-equiv/ $\mathrm{hr}$ after vagotomy, a mean reduction of $65 \%$.

\section{Discussion}

In this study vagal denervation (decentralization) of the stomach of patients with duodenal ulcer caused a reduction in acid and pepsin output both in the basal state and after stimulation with the cholinergic drug carbachol. This finding apparently conflicts with the finding in a previous study that vagal denervation of Pavlov pouches in dogs rendered the pepsin-secreting cells supersensitive to cholinergic stimuli (Andersson and Grossman, 1965). These previous investigators were, however, able to administer a wide dose range of urecholine by continuous intravenous infusion to dogs who tolerated large doses well, whereas in the present study it was only possible to give small subcutaneous doses of a similar cholinergic agent to human subjects because of unpleasant side effects to larger doses. In fact, while Andersson and Grossman were able to stimulate the pouches of their dogs to secrete at near maximum levels with urecholine, the acid output achieved after cholinergic stimulation in the present study amounted to only $20 \%$ of the peak acid output to pentagastrin in the five patients.

Nevertheless it is possible to draw some conclusions from the present results. Vagal denervation of the parietal cells and the pepsin-secreting cells did not cause them to become supersensitive to cholinergic stimuli, ie, doses of carbachol which were subthreshold before vagotomy did not become threshold after vagotomy, not was there an increase after vagotomy in the secretory response to submaximal doses. On the contrary, both acid and pepsin outputs were significantly reduced, implying that the sensitivity of the cells was reduced by complete vagal denervation. It is possible that had large submaximal doses been given a supersensitivity state would have been unmasked, but this cannot be readily studied in man.

The basal levels of both acid and pepsin were reduced after truncal vagotomy and although the $44 \%$ reduction of pepsin output was not significant it was of the same order as the reduction of acid output. Possibly statistical significance would have been reached with larger numbers of subjects. The reduction of the basal pepsin output after vagotomy was not the sole reason for the reduced response to carbachol as the reduction was still observed when the pre- and post-vagotomy basal outputs had been subtracted from the total outputs. Alternative explanations for the differences from the findings of Andersson and Grossman are differences in experimental design and the possibility that the human stomach in these circumstances behaves differently from that of the dog. The chief difference in experimental design is that whereas truncal vagotomy was performed in the present study Andersson and Grossman vagally denervated only the acid-secreting part of the stomach, leaving the remainder of the upper gastrointestinal tract with an unaltered vagal supply. Several species differences have been observed between the behaviour of the pepsin cells in man and the dog. The most striking is that whilst in man there is a basal secretion of pepsin it is either absent or at very low rates in the dog (Hirschowitz and Robbins, 1966). Histamine appears not to stimulate pepsin in dogs, while doing so in man (Linde, 1950), and the response to $2 \mathrm{DG}$ is much more short lived and of a different pattern in the dog (Duke, Hirschowitz, and Sachs, 1965).

The present results offer no support for the proposal that denervation supersensitivity of the pepsin cells could form the basis of a test for completeness of vagotomy in man.

I wish to thank Mr J. Fleming for technical assistance, Staff Nurses Pope and King for help with the tests, and Miss Stephanie Nichols for secretarial assistance.

\footnotetext{
References

Andersson, S., Grossman, M. I. (1965). Effect of vagal denervation of pouches on gastric secretion in dogs with intact or resected
} antrums. Gastroenterology, 48, 449-462. 
Baron, J. H. (1969). Dose-response to insulin hypoglycaemia of human gastric acid. Brit. J. Surg., 56, 383-4.

Cannon, W. B. (1939). A law of denervation. Amer. J. med. Sci., 198, 737-750.

Duke, W. W., Hirschowitz, B. I., and Sachs, G. (1965). Vagal stimulation of gastric secretion in man by 2-deoxy-D-glucose. Lancet, 2, 871-876.

Grossman, M. I., and Marks, I. N. (1960). Secretion of pepsinogen by the pyloric glands of the dog with some observations on the histolcgy of the gastric mucosa. Gastroenterology, 38, 343-352.
Hirschowitz, B. I., and Robbins, R. C. (1966). Direct inhibition of gastric electrolyte secretion by insulin, independent of hypoglycaemia or the vagus. Amer. J. dig. Dis., 11, 199-212.

Hollander, F. (1948). Laboratory procedures in the study of vagotomy (with particular reference to the insulin test). Gastroenterology, 11, 419-425.

Linde, S. (1950). Studies on the stimulation mechanism of gastric secretion. Acta physiol. scand., 21, Suppl., 74.

Tinker, J. (1969). ChM Thesis, University of Witwatersrand, p. 142. 